
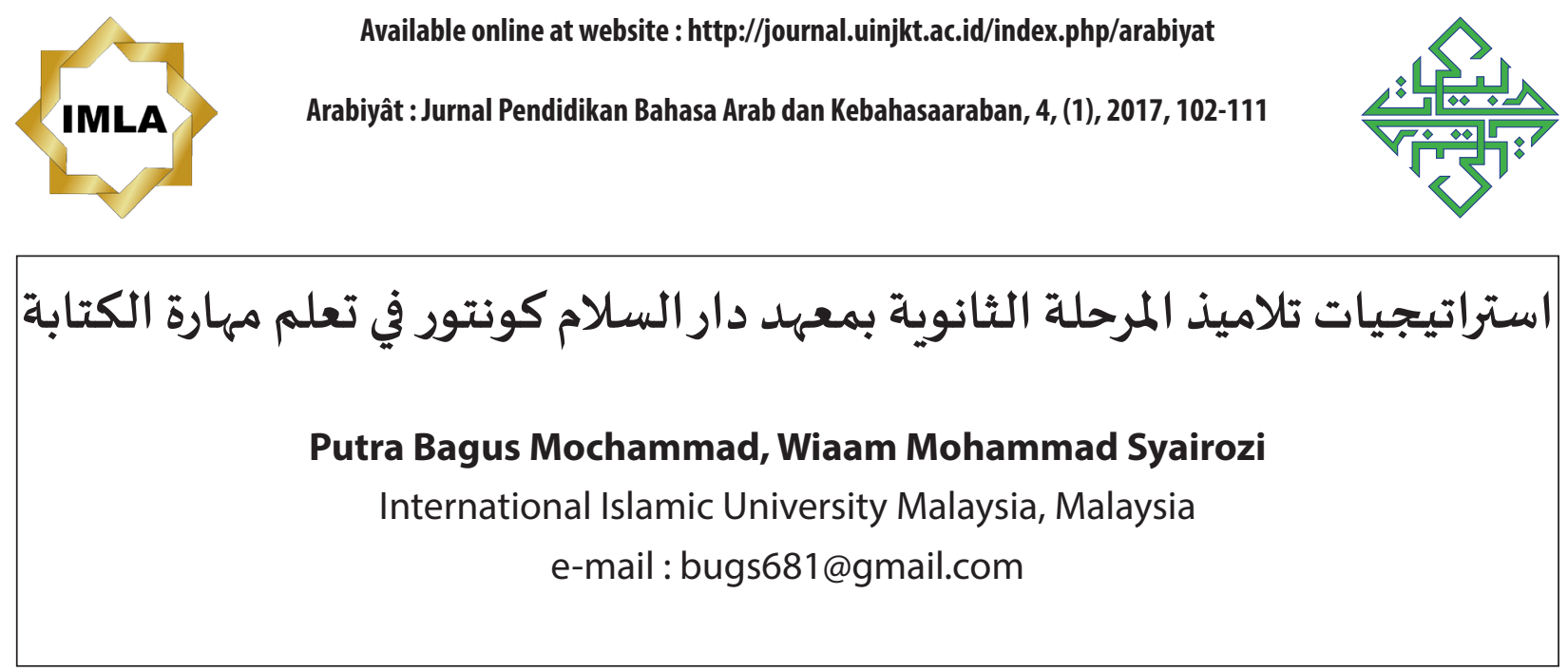

Naskah diterima: 10 Februari 2017, direvisi: 13 Maret 2017, disetujui: 12 April 2017.

\begin{abstract}
This study attempted to investigate the strategies used by high school students in writing Arabic compositions, problems they confronted, and differences strategies used by the students with highest and lowest scores. The samples of this study were fifth-grade students of Darussalam Islamic Boarding School, i.e., three students with high achievements and three with low ones. Data collection techniques were used, namely thinking-aloud protocol, interview and observation. Specific processes and strategies were categorized using coding schemes adopted from Yap (1999). The result of this study revealed that the problems mostly faced by the students in writing an Arabic composition were understanding the topic and generating the idea to create a good sentence. Moreover, the study found that students were unable to select proper words, to figure out appropriate sentences and to construct simple sentences. The most commonly-used strategies were repeating words, making sentences, taking down notes and translating.
\end{abstract}

Keywords: Arabic compositions, writing strategies, thinking-aloud protocol

\begin{abstract}
Abstrak
Tujuan penelitian ini adalah untuk mengetahui strategi yang digunakan oleh siswa Aliyah saat menulis karangan berbahasa Arab, problem yang mereka hadapi, dan perbedaan strategi menulis antara murid dengan pencapaian nilai tertinggi dan terendah. Sampelnya diperoleh dari tiga siswa kelas lima Pondok Pesantren Darussalam dengan dengan nilai tertinggi dan tiga lainnya dengan nilai rendah. Peneliti ini menggunakan tiga teknik pengumpulan data yaitu thinking-aloud protocol, wawancara dan observasi. Proses dan strategi tertentu dikelompokkan menggunakan prosedur berdasarkan skema pengkodean yang diadopsi dari Yap (1999). Hasil penelitian ini mengungkapkan bahwa problem yang dihadapi oleh sebagian besar siswa saat menulis karangan berbahasa Arab yaitu memahami topik dan menghasilkan sebuah ide. Selain itu, penelitian ini juga mengungkapkan bahwa siswa tidak mampu memilih kata, mengkonfigurasi kalimat yang tepat dan membuat kalimat yang sederhana karena kekurangan kosa kata bahasa Arab. Strategi mengulangi kata-kata, latihan membuat kalimat, membuat catatan dan menerjemahkan merupakan strategi yang paling umum digunakan oleh siswa.
\end{abstract}

Kata Kunci: karangan berbahasa Arab, strategi menulis, thinking-aloud protocol

How to Cite: Mochammad, Putra Bagus. Wiaam Mohammad Syairozi. "Istiratijiyat Thullab al-Marhalah al-Tsanawiyah fi Kitabah al-Ta'bir al-'Arabi" Arabiyat : Jurnal Pendidikan Bahasa Arab dan Kebahasaaraban [Online], Vol. 4 No. 1 (31 Juni 2017)

Permalink/DOI: http://dx.doi.org/10.15408/a.v4i1.5329 
ونظم الشعر.

إن كتابة الإنشاء الجيد ليست موهبة إلهياة، إنما

هي قدرة مكتسبة. كما أنها هي اللغة التي يستقبلها الفرد من مجتمعاه. فلا يمكن للفرد أن يصبح نسخة جديدة من المتكلمين بتلك اللغة، بل لابد من عامل متفوق يقوم في كل مجال من مجالات الحياة. فليس مستحيلا للطالب الوصول إلى الكتابة الجيدة، لأن الإنشاء أصلا هو تعبير عما نفكر فياه، أو عما نحس باء من مشـاعر.

يواجه كثير من التلاميذ تحديات في مهارة الكتابة في اللغة الأولى أو الثانية. قرر(1999) Nunan أن الصعوبات التي تواجـ التلاميذ عند تعلم اللغة هي إنتاج الفصاحة، وتماسك اللغة، وإنتاج الكتابة الجيدة. وتعتبر مهارة الكتابة من المهارات الرئيسية من بين المهارات الأربعة (الاستماع، والكلام، والقراءة، والكتابة)، وهذه المهارة لها دور بارز في مساعدة التلاميذ على تنمية قدراتهم اللغوية. وهي أيضيا مهارة عقلية معقدة تقوم على الخلق والإبداع، حيث يتم من خلالها تحويل الأفكاروالمعاني الموجودة في ذهن الكاتب إلى رموز خطية في صورة من صور التعبير الكتابي المؤثرة. وقد أشـار Zamel أن الأعمال الكتابية ذات طبيعة خلاقة تستدعي إعمال الذهن، وعمق المعالجـة، وحسن التناول للموضيوع أو المشكلة التي تلدور حول الكتابة.

إن مراجعة البحوث عن كتابة التعبير لم تقدر على حل جميع مشكلات التلاميذ في عملية الكتابة.

${ }^{2}$ V. Zamel, "Writing: The Process of Discovering Meaning", TESOL Quarterly, 16 (2), 1982, 195-209..

اللغة وسيلة يعتمد عليها الإنسان للتعبير عن أفكاره بالاتصال بين الأفراد والجماعات فكريا أو اجتماعيا. وهي أيضا مظهر من مظاهر المجتمع ونشاطاته حيث تميز أفراد المجتمع عن غيرهم. ولا يستطيع المرء تعرف اللغة أو الوصهول إليها إلا من خلال التعامل بها بالتعبير عما في الحياة من عقائد وأفكارومشاعرداخلية. ومع ذلك، فإن اللغة ليست وسيلة للتعبير عما في نفس المتكلم والكاتب فقط، بل أيضا وسيلة لاستثارة المستمع والقارئ وتحريك وجدانياتهما ودفعها إلى الحركة والعمل والاستجابة والتلبية لأثر الكلام المستمع إليه أو المقروء. وإن اللغة بمهاراتها الأربع تشكل أهمية كبيرة لدى طلبة ومدرسي اللغة، لكون الهدف من تعلمها وتعليمها هو القدرة على الاتصال بها كلاما وكتابة. وهي منهج الإنسان في التفكير وفي الوصول إلى العمليات والمدركات الكلية. فالإنسـان عندما يتكلم فإنها يستخدم ألفاظا وجملا، وذلك يعنى أن اللغة نظام للتعبير، وهي كذلك نظام التجارب الشعورية ويظهرذلك أكثرفي الأدب والشعر. إذا كان الغرض من اللغة هو التعبير بالاتصال مع الناس فيكون ذلك عن طريق المحادثة والمناقشـة وقص القصص، والأخبار، وإلقاء المعلومات. وإذا كان الغرض للتعبير عن الأفكار فيكون ذلك عن طريق كتابة المقالات وتأليف القصص والتراجم

1 'Ali Ahmad Madkur, Tadrîs Funûn al-Lughah al'Arabiyyah, (Kairo: Dâr al-Fikr al-'Arabi, 2006). 
قام الباحثون (1975، Rubin، بالبحث في

استراتيجيات التعلم، وأثبتت أن هذه البحوث

تسـاعد عملياة تعلم التلاميذ في اللغة الثانية. وقد

أشار Oxford، Chamot ${ }^{10}$ ، ${ }^{11}$ Cohen وغيرهم من

الباحثين إلى أن هناك عوامل تؤثر في استراتيجيات

التلاميذ، وهي: اللغة الأولى، ودرجة استيعاب اللغة،

والجنس والتحريض. ورأى الباحثون أن الكتابة

في اللغة الثانية هي عملية معقدة تحتاج إلى إعمال

الذهن وتضمن العمليات والاستراتيجيات المتنوعاة،

فاستخدام الاستراتيجيات في كتابة التعبير تكون

عاملا من عوامل إنتاج الكتابة الجيدة.

يصعب لمتعلمي اللغة الثانية القدرة على كتابة

التعبير، وقد شـاع وكثر البحث عن هذا الموضيوع من

قبل الباحثين. وذلك لأن هذه القدرة تنطوي على

عدد من الأنشطة المعرفية وفوق المعرفية كالعصف

الذهني، والتخطيط، والتحديد، والتنظيم،

والصياغة، والمراجعة. فالمتعلمون ذوي المستويات

المتقدمة يستخدمون أنواع الاستراتيجيات لحل

مشكلاتهم في الكتابة.12. ويجب أيضيا على المدرسين

أن يساعدوا التلاميذ بإرشادهم إلى استخدام

8 J. Rubin, "What The "Good Language Learner" Can Teach Us", TESOL Quarterly, 9 (1), 1975, 41-51.

${ }^{9}$ R. L. Oxford, Teaching and Researching La guage Learning Strategies, (Britain: Pearson Education Limited, 2011)

${ }^{10}$ A. U. Chamot \& L. Kupper, "Learning Strategies in Foreign Language Instruction", Foreign Language Annuals, 22. 1989,13-24.

${ }^{11}$ A. D. Cohen \& E. Macaro, Language Learner Strategies: 30 Years' Research and Practice, (United Kingdom. Oxford University Press, 2007).

${ }^{12}$ P. Maftoon, "Good Language Learner: A Case Study of Writing Strategies", Theory and Practice in Language Studies, Vol. 2, No. 8, 2012.
ومن أسباب ضعف التلاميذ هو عدم فهمهم عن الموضيوع. وجدت Raimes في دراستها أن الكاتب الضعيف يقضي 17.5 دقيقة في قراءة الموضوع لعدم فهمهم للكلمة. واكتشف غيرها من الباحثين أن التلاميذ لم يقدروا على اختيار الكلمة المناسبة مما أدى إلى كتابة كلمة غير مطابقة بالمعنى المطلوب. وفسرا Raimes ${ }^{5}{ }^{4}$ Zamel أن القلق يظهر أحيانا في نفس الكاتب الضعيف عند عملية الكتابة، بخلاف

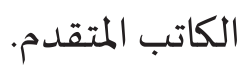

ومع ذلك، فإن من أبرز ضعف التلاميذ في

التعبيرهو ضعف الأفكاروالاضطراب في ترتيبها وعدم القدرة على الربط بينها بطريقة منطقية وعدم التركيز الرئيسي للموضوعُ. وتطابق ذلك مع رأي الباحث المؤيد لوجها النظر السابق إذ أن ما يلمسـه ويلاحظه من اضطراب وخلط وارتباك في صياغة الأفكار عند محاولة معظم التلاميذ في الإجابة على أي سؤال بحكم عمله الجامعي في التدريس يفوق كثيرا حد التوقع، وكذلك نجد الكثير من التلاميذ ينفرون من درس التعبير لسيطرة إحساسهم بالإخفاق في نقل

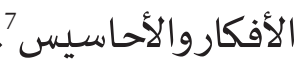

${ }^{3}$ A. Raimes, "What Unskilled ESL Students Do as They Write: A Classroom Study of Composing", TESOL Quarterly, 19 (2), 1985, 229-258.

${ }^{4}$ V. Zamel, "Writing: The Process of Discovering Meaning", 195-209.

${ }^{5}$ V. Zamel, "Writing: The Process of Discovering Meaning", 195-209.

${ }^{6}$ Sami 'Ali al-Khalaq, Al-Lughah wa al-Tafkîr alNaqid Usus Nazhariyyah wa Istirâtîjiyyah Tadrîsiyyah, (Amman: Dârul al-Ma'âshirah wa al-Nasyr, 2010).

7 Fahd Kholil Zaid, Asâlîbu Tadrîs al-Lughah al'Arabiyyah baina al-Mahârah wa as-Syu'ûbah, (Amman: Dâr al-Yazuri al-'Ilmiyah, 2006). 


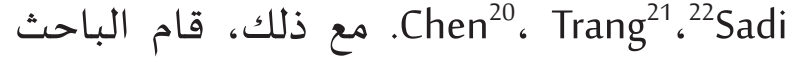

ببحث عن مشكلات التلاميذ عند كتابة التعبير

وأنواع استراتيجياتهم، وهل هناك فرق بين التلاميذ

المتقدمين والتلاميذ المتأخرين.

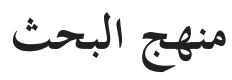

استخدم الباحث العينة الصغيرة من الحالات

أو الوحدات أو الأنشطة للحصول على المعلومات

التي تساعد في فهم الأمور التربوية. والهدف الأسـاسي

منها هو الحصول على توضيح وتعمق في فهم الباحث

للمشكلة. وذكرعثمان (2006) أن في البحث الكيفي

لا يحتاج إلى عدد كبير من أفراد العينة، مادام هؤلاء

الأفراد القليلين يستطيعون على توكيد كمية كافية

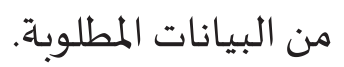

و لذلك كانت عينة البحث مأخوذة من تلاميذ

الصف الخامس بمعهد دار السلام كونتور فونوروكو

للعام الدراسي 1437-1436هـ/2016-2015م. ثلاثة

طلاب من ذوي التحصيل العالي، وثلاثة آخرين من

$$
\text { ذوي التحصيل المتدني. }
$$

وأما سبب اختيار الباحث لهذه العينة فهوحاجة

البحث إلى الكشف عن استراتيجيات كتابة التعبير

${ }^{20}$ Y. Chen, "Study of The Writing Strategies Used by Chinese non English Majors", Theory and practice in language studies, Vol. 1, No. 3, 2011, 245-251

21 Trang and Hoa Thi Mai, "Student Writing Process, Perceptions, Problems, and Strategies in Writing Academic Essays in a Second Language: a Case Study", VNU Journal of Science: Foreign Language, 24, 184-197, 2008.

${ }^{22}$ F. F Sadi, and J. Othman, "An Investigation into Writing Strategies of Iranian EFL Undergraduate Learners", World Applied Sciences Journal, Vol. 18 (8), 2012, 1148-1157.
الاستراتيجيات عند كتابة التعبير وفهم مدى قدرة

التلاميذ فيها. ومن هنا تتضح أهمية فهم المدرسين لاستراتيجيات التلاميذ عند كتابة التعبيروتأثيرها في حل مشكلاتهم في مهارة الكتابة.

وإن البحوث التي أجريت في مهارة الكتابة

بإندونيسيا تولي اهتماما كبيرا بطرق التدريس،

وإهمال العوامل النفسية لدى التلاميذ، منها بحث

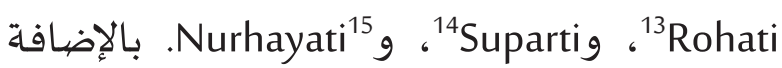

إلى أن البحوث التي أجريت في استراتيجية كتابة

التعبير الإنشائي معظمها تدور حول اللغة الإنجليزية،

${ }^{18}$ Lan، Alhaisoni ${ }^{19}$ ، ،

13 Rohati, "Strategi Pembelajaran Keterampilan Bahasa Terpadu dengan Teknik Paraphrase untuk Meningkatkan Kemampuan Apresiasi dan Menulis Puisi", Edisi Khusus, No. 2, 2011

${ }^{14}$ Suparti, "Strategi Pembelajaran Menulis di Sek lah Dasar Kelas IV", Didaktika, Vol. 2. No. 1, 2007, 259-271.

15 Nurhayati, "Berbagai Strategi Pembelajaran Bahasa dapat Meningkatkan Kemampuan Berbahasa Siswa", Jurnal Bahasa \& Sastra, Vol 9. No. 2, 2008.

${ }^{16}$ Al-Jasyi, "Istikhdâm Thalabah al-Shaf al-Awwal al-Tsanâwi li Mahârah 'amaliyah al-Ta'bîr al-Kitâb fi Mâdah al-Lughah al-Injlîziyah: Dirâsah Maidâniyah fî Madâris Madînah Damaskus al-Rasmiyah", Majallah Jâmi’ah Damaskus, Al-Mujallad 26, 2010.

17 M. R. Abdullah, "Writing Strategies of Malaysian ESL Undergraduate Engineering Learners", International Journal of Engineering \&Technology, Vol; 11, No. 02, 2011.

${ }^{18}$ Y. F. Lan, "Effects of Guided Writing Strategies on Students' Writing Attitudes based on Media Richness Theory", The Turkish Online Journal of Educational Technology, Vol. 10, No. 4, 2011.

19 E. Alhaisoni, "A Think-aloud Protocols Investigation of Saudi English Major Students' Writing Revision Strategies in L1 (Arabic) L2 (English)", English Language Teaching, Vol. 5. No. 9, 2012. 
ومع ذلك، قام الباحث بمقابلة الاسترجاع

وهي المصددر الثاني للبحث فهي توفر معلومات عن

استراتيجيات التلاميذ عند كتابة التعبير. واستخدم

الباحث هذه الأداة لسببين. الأول، أن هذه الأداة

هي أداة إضافية تساعد أداة التفكير بصوت عال اهده،

(Think Aloud Protocol)

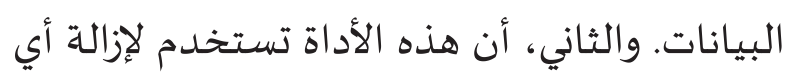

غموض والتباس وجد في أداة التفكير بصوت عال.

\section{النتائج والاقتراحات}

تناول الباحث نتائج هذا البحث من تحليل تسخة تدوين التفكير بصوت عال وأداة مقابلة الاسترجاع. ووفقا لأهداف البحث الثلاثة وهي كشف الاستراتيجيات المستخدمة لدى التلاميذ في مهارة الكتابة، والتعرف على المشكلات التي يواجهها التلاميذ، ثم الفرق بين التلاميذ المتقدمين والمتأخرين

$$
\text { في استخدام الاستراتيجيات. }
$$

وبعد البحث، رأى الباحث أنّ المشكلات التي

واجهها التلاميذ عند كتابة التعبير هي عدم فهم موضوع التعبير، وتكوين الفكرة، وهذا يؤدي إلى

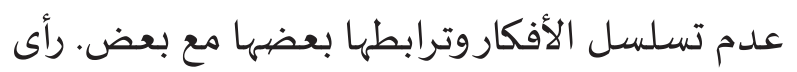
الباحث أن التلاميذ قاموا بالتخمين لفهم المهمة. ومع ذلك، كثيرا ما وجد في هذا البحث أن التخمين خاطئ. وكما أن التلاميذ لم يركزوا على دقة الكلمة،

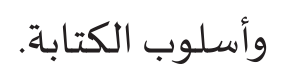

ومن المشكلات الأخرى أن التلاميذ لم يقدروا على تنظيم الأفكار. وقد كتبوا كل ما خطر على
لتلاميذ الصف الخامس ذوي المستوى المتقدم والمتدني. ولأن هؤلاء تلاميذ المرحلة العالية بمعهد دار السلام كونتور فونوروكو، ولا تقلّ خبرتهم في كتابة

$$
\text { التعبير العربي عن ثلاث سنوات. }
$$

الإلجراءات

قام الباحث بتدريب التلاميذ على التفكيربصوت عال اقتباسا من الإجراءات المستخدمة في الدراسات

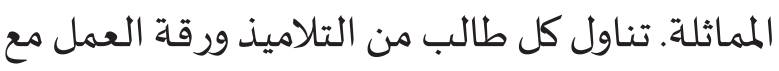
بعض التوضيحات عنها. ثم أخبر الباحث التلاميذ أنه يريد أن يعرف ماذا يفكرون أثناء الكتابة. لابد للطلبة أن يكتبوا الإجابة باللغة العربية ولكن يجوز لهم استخدام اللغة الإندونيسية عند التفكيربصوت

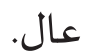

عقد التدريب مرتين، وذلك للتركيز على الجمل في التدريب الأول، والتركيز على الفقرات في التدريب الثاني، ثم إلى إنشاء المقالة عند جمع البيانات. بدأ الباحث في تحليل البيانات بقراءة نخسـة التفكير بصوت عال التي كتبه الباحث لوضعها في التصنيفات المعينة. فقد حدد الباحث السلوك المهيمن لوضع رموز استراتيجيات التفكيربصوت عال. ومن السلوك المهيمن القراءة، والكلام، والكتابة، مبنية على رموز

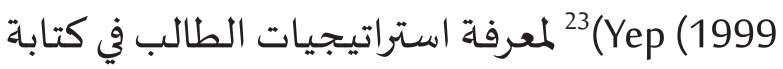
الرسالة. وقد قام الباحث بتعديل بعض المصطلحات استنادا إلى تصنيف أكسفورد.

${ }^{23}$ Yap, "Strategies for Writing Business Letters Among Selected Weak ESL Learners at University Putra Malaysia", Unpublished Master Thesis: University of Malaya, 1999. 
أذهانهم دون مراعاة الترابط بين الجمل وبين الفقرات. وهذا لأن التلاميذ لم يتعودوا على كتابة العناصر قبل كتابة الإنشاء. ومع ذلك، رأى الباحث أن التلاميذ واجهوا مشكلة في استخدام المفردات وتكوين الجمل المناسبة لقلة الثروة اللفظية لديهم. ولحل تلك المشكلة قام التلاميذ باستدعاء كل ما تعلموه داخل الفصل وخارجه من المفردات ويختارون الكلمة أو الجملة البسيطة. كل هذه تطابق بما وجد Raimes.24 ويظهر أن التلاميذ قد استخدموا استراتيجيات عديدة تتراوح بين سبع وثلاثين (37) ومائة وإحدى عشرة (111) ، وهي كما يلي: الجدول رقم (1): مجموع الاستراتيجيات المستخدمة لجميع أفراد العينة:

\begin{tabular}{|c|c|}
\hline عدد الاستراتيجيات المستخدمة & 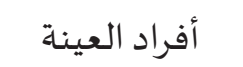 \\
\hline 74 & الطالب الآول \\
\hline 111 & الطالب الثاني \\
\hline 84 & الطالب الثالث \\
\hline 37 & الطالب الرابع \\
\hline 67 & الطالب الخامس \\
\hline 37 & الطالب السـادس \\
\hline 410 & المجموع الكلي \\
\hline
\end{tabular}

من الجدول رقم (1) ظهر أن مجموع الاستراتيجيات المستخدمة لدي التلاميذ أربعمائة وعشر (410) استراتيجية. استخدم الطالب الثاني 111 استراتيجية، وهذا يمثل من أكبر عدد حيث أن هذا التلميذ من التلاميذ ذوي التحصيل العالي. وعلى حين استخدم التلميذ الرابع والسـادس 37 استراتيجية، وهذا يمثل أقل عدد. نرى من الجدول كذلك أن التلميذين استخدما أقل من خمسين استراتيجية، كلاهما من الفصل الخامس ذوي التحصيل المتدني. وأن كل التلاميذ استخدموا استراتيجية المعرفية أكثرمن الاستراتيجيات الأخرى، حيث بصورة لافتة للنظر بلغ عددها إلى ثلاثمائة وأربع وتسعين (394) استراتيجياة. ويأتي بعد ذلك استراتيجية فوق المعرفية بثماني (8) استراتيـجيات. وأقل استراتيجية استخدمها التلاميذ هي التأثيرية.

24 Yap, "Strategies for Writing Business Letters Among Selected Weak ESL Learners at University Putra Malaysia" 


$$
\text { وأما استراتيجية التعويضية والاجتماعية فلم تستخدما على الإطلاق. (الجدول 2). }
$$

\begin{tabular}{|c|c|c|c|c|c|c|}
\hline التأثيرية & الاجتماعية & فلمعرقية & التعويضية & التذكرية & المعرفية & أفراد العينة \\
\hline 0 & 0 & 1 & 0 & 0 & 73 & الأول \\
\hline 0 & 0 & 3 & 0 & 0 & 108 & الثاني \\
\hline 0 & 0 & 0 & 0 & 1 & 83 & الثالث \\
\hline 1 & 0 & 1 & 0 & 0 & 35 & الرابع \\
\hline 0 & 0 & 3 & 0 & 6 & 58 & الخـامس \\
\hline 0 & 0 & 0 & 0 & 0 & 37 & السـادس \\
\hline 1 & 0 & 8 & 0 & 7 & 394 & المجمموع الكلي \\
\hline
\end{tabular}

ويلاحظ الباحث أن التلاميذ استخدموا أربع عشرة استراتجية من اثنتين وعشرين استراتيجية. ونرى أن استراتيجية التكرارواستراتيجية التفكيرفي بناء الجملة من الاستراتيجية المعرفياة، احتلتا المرتبة الأولى في

\begin{tabular}{|c|c|}
\hline أنواع الاستراتيجيات & تدوين الحرفي \\
\hline التكرار & $\begin{array}{l}\text { Mencari ilmu dan pengetahuan, ilmu dan pengetahuan, mencari ilmu } \\
\text { dan pengetahuan }\end{array}$ \\
\hline التكرار & 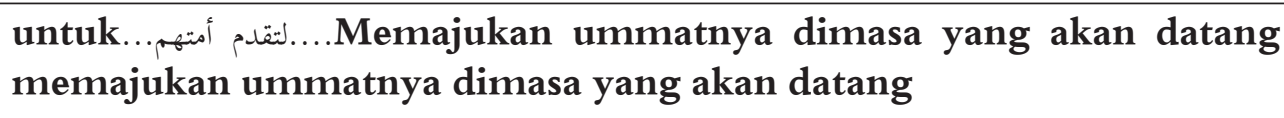 \\
\hline المراجعة & في المستقبل.....في بناء المستقبل \\
\hline استجواب النفس & $\begin{array}{l}\text { siswa, membentuk membangun masa depan alam islam,... بeee...apa ya?.... } \\
\text { ؟ya ماذا....apa?... eee.....alam al-islam }\end{array}$ \\
\hline التكرار & 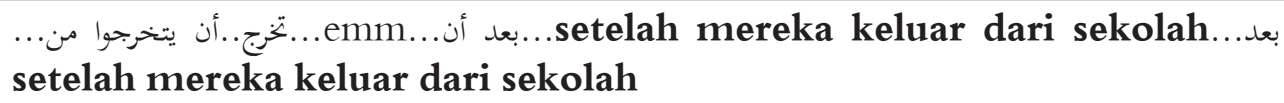 \\
\hline التكرار & $\begin{array}{l}\text { siswa mempunyai peran...emm... dalam...Dalam membangun alam islam } \\
\text { yang penting dalam membangun alam islam }\end{array}$ \\
\hline 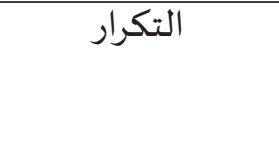 & 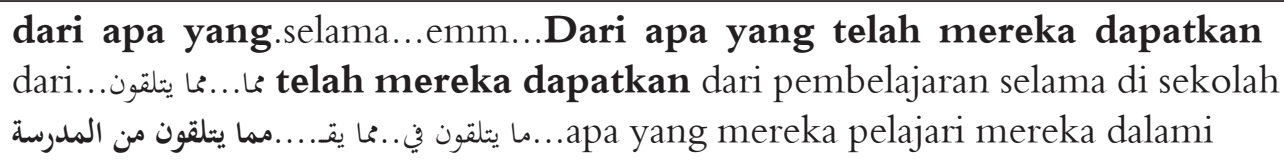 \\
\hline
\end{tabular}

$$
\text { استخدامها لدى العينة، حيث بلغ عددهما ثلاث وثمانين (83) مرة. }
$$

\begin{tabular}{|c|c|}
\hline أنواع الاستراتيجيات & تدوين الحرفي \\
\hline التفكير في بناء الجملة & 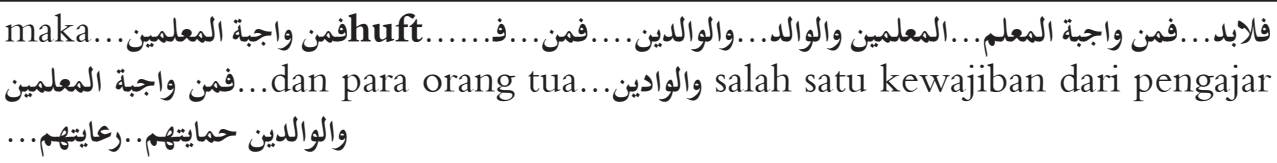 \\
\hline
\end{tabular}

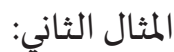




\begin{tabular}{|c|c|}
\hline التفكير في بناء الجملة & 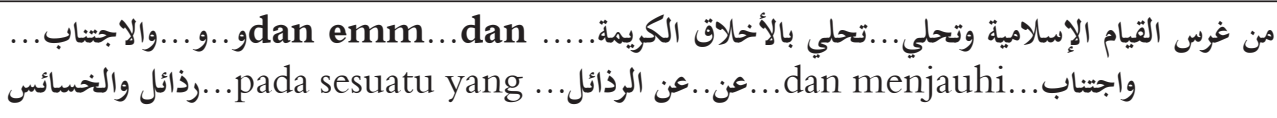 \\
\hline التفكير في بناء الجملة & 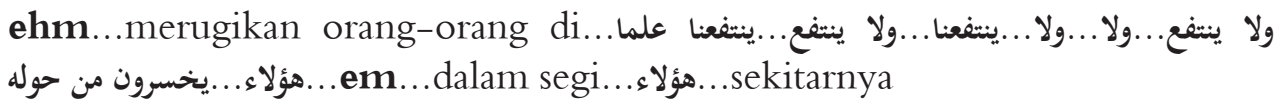 \\
\hline 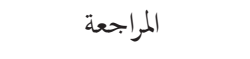 & ولا ينتفع....ينتفعنا علما \\
\hline التفكير في بناء الجملة & 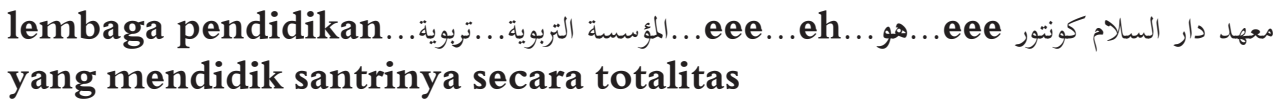 \\
\hline 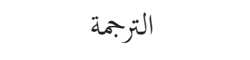 & المؤسسة التربوية...تربوية...1embaga pendidikan \\
\hline
\end{tabular}

بينما تقييم المهماة من الاستراتيجيات المعرفياة وذكر العبارات المشجعاة من الاستراتيجيات التأثيرية فهما

من أقل الاستراتيجيات استخداما، حيث استخدمتا مرة واحدة لكل منها. (الجدول 3)

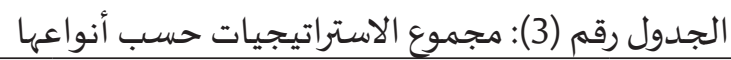

\begin{tabular}{|c|c|c|c|}
\hline المجموع الكلي & المجموع & & أنواع الاستراتيجيات \\
\hline \multirow[t]{11}{*}{ rqs } & . & التلخيص & الاستراتيجيات المعرفية \\
\hline & $7 V$ & الترجمة & \\
\hline & N & التكرار & \\
\hline & $\varepsilon 0$ & المراجعة & \\
\hline & . & التمرين في بناء الجملة & \\
\hline & $\varepsilon$ & التفكيرفي بناء الأفكار & \\
\hline & $\lambda r$ & التفكيرفي بناء الجملة & \\
\hline & $V \varepsilon$ & 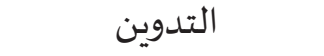 & \\
\hline & r & 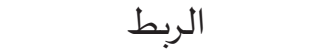 & \\
\hline & $r \varepsilon$ & استجواب النفس & \\
\hline & r & الاستنتاج & \\
\hline \multirow[t]{9}{*}{$\wedge$} & $\varepsilon$ & فهم الغرض من المهمة & الاستراتيجية فوق المعرفية \\
\hline & - & 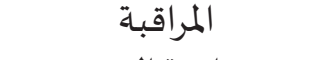 & \\
\hline & · & مراقبة الفهم & \\
\hline & · & أسلوب المراقبة & \\
\hline & . & تقييم الفهم & \\
\hline & 1 & تقييم المهمة & \\
\hline & r & تقييم النتاج & \\
\hline & · & تقييم القدرة & \\
\hline & $\cdot$ & كتابة المسودة & \\
\hline V & V & التوجيه الذاتي & الاستراتيجية التذكرية \\
\hline 1 & 1 & ذكر العبارات المشجعة & الاستراتيجية التأثيرية \\
\hline
\end{tabular}

ظهرمن نتيجة هذا البحث أن من مشكلات التلاميذ في كتابة التعبير العربي هي عدم فهم المهمة، رغم أهمية ذلك كتابة التعبير. فضعف فهم المهمة يججعل الكاتب يكتب على غير هدى، لا يراعي نظام الأفكارولا تسلسلها. وعلى المدرس أن يمرّن التلاميذ على كتابة الإنشاء بالموضوعات التي تتعلق بما يدور حولهم، حتى يتمكن لهه إظهار المشاعروالأحاسيس والعواطف الجياشـة، فتؤثرفي نفس القارئ. 
Cohen, A. D \& Macaro, E. Language Learner Strategies: 30 Years' Research and Practice. United Kingdom: Oxford University Press, 2007.

Al-Jasyi, "Istikhdâmu Thalabah al-Shaff alAwwal al-Tsânawîli Mahârah 'Amaliyyah al-Ta'bîr al-Kitâbî fî Mâddati al-Lughah al-Injlîziyah", Dirâsah Maidâniyyah fî Madâris Madînah Damaskus al-Rasmiyyah", Majallatu Jâmi'atul Damaskus, al-Mujallad. 26, 2010.

Al-khalaq, Sâmi 'Ali. Al-lughah wa altafkîr al-Nâqid Usus Nazhariyyah wa Istiratîjiyyah Tadrîsiyah, 'Aman, Urdun: Dâr al-Mu'âshîrah wa al-Nashr, 2010.

Lan, Y. F. "Effects of Guided Writing Strategies on Students' Writing Attitudes based on Media Richness Theory", The Turkish online Journal of Educational Technology, Vol. 10, No. 4, 2011.

Madkûr, 'Ali Ahmad. Tadrîs Funûn al-Lughah al-'Arabiyyah, Kairo: Dâr al-fikr al-'arobî, 2006.

Maftoon, P. "Good Language Learner: a Case Study of Writing Strategies", Theory and Practice in Language Studies, Vol. 2, No. 8, 2012.

Nurhayati. "Berbagai Strategi Pembelajaran Bahasa dapat Meningkatkan Kemampuan Berbahasa Siswa", Jurnal Bahasa \& Sastra, Vol 9. No. 2, 2008.

Oxford, R. L. Teaching and Researching Language Learning Strategies. Britain: Pearson Education Limited, 2011.

Raimes, A. "What Unskilled ESL Students Do as They Write: A Classroom Study of Composing", TESOL Quarterly, 19 (2), 1985.

Rohati. Strategi Pembelajaran Keterampilan Bahasa Terpadu dengan Teknik

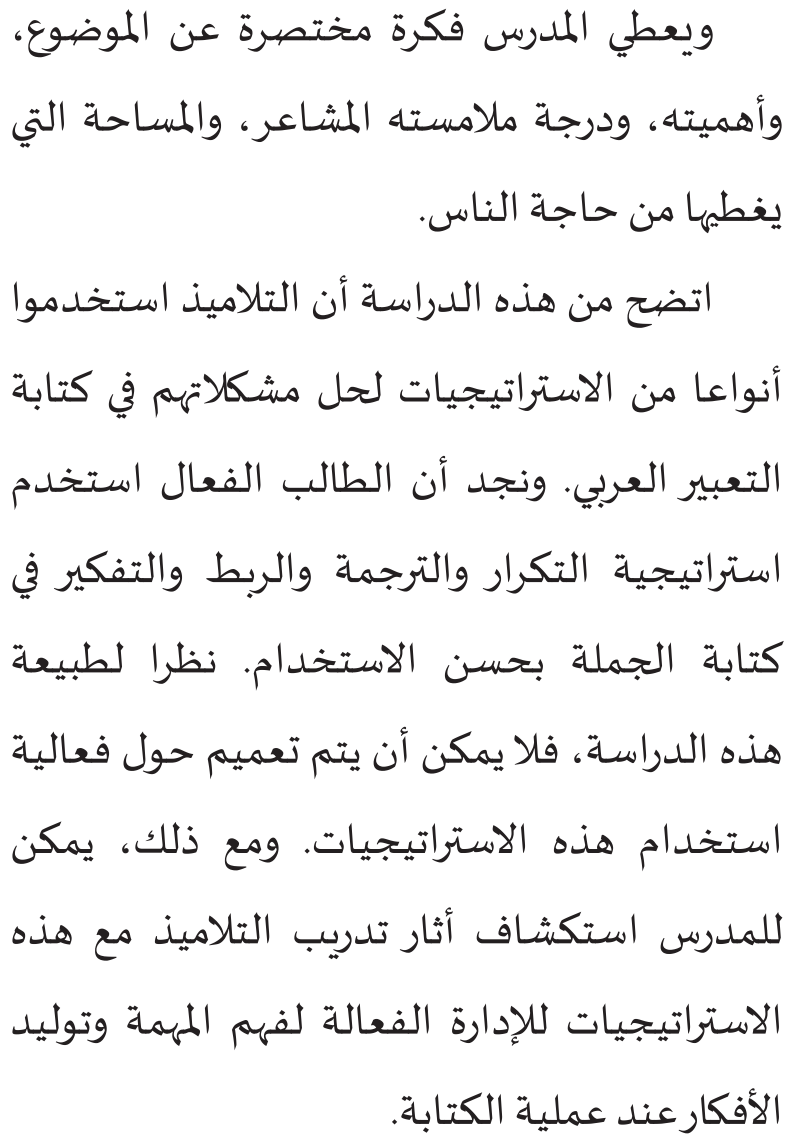

Abdullah, M. R. "Writing Strategies of Malaysian ESL Undergraduate Engineering Learners", International Journal of Engineering \& Technology, Vol; 11, No. 02, 2011.

Alhaisoni, E. "A Think-aloud Protocols Investigation of Saudi English Major Students' Writing Revision Strategies in L1 (Arabic) L2 (English)", English Language Teaching, Vol. 5. No. 9, 2012.

Chamot,A.U\& Kupper, L. "Learningstrategies in foreign language instruction", Foreign Language Annuals, 22, 1989.

Chen, Y. "Study of the Writing Strategies Used by Chinese non English Majors", Theory and Practice in Language Studies, Vol. 1, No. 3, 2011. 
Arabiyât Jurnal Pendidikan Bahasa Arab dan Kebahasaaraban, 4 (1), 2017

Tamara Gasanbekova. "Culturogical Aspects of Teaching (Based on The Arabic Language", The II International Conference, (Methods of Teaching Oriental Languages: Actual Problems and Trends). Moscow, May 2014.

Trang, Luong Quynh, Hoa, Thi Mai. "Student Writing Process, Perceptions, Problems, and Strategies in Writing Academic Essays in a Second Language: a Case Study", VNU Journal of Science, Foreign Language 24, 2008.

Yap. "Strategies for Writing Business Letters among Selected Weak ESL Learners at University Putra Malaysia", Unpublished Master Thesis. University of Malaya, 1999.

Zaid, Fahd Kholîl. Asâlib Tadrîs al-Lughah al-Arabiyyah baina al-Mahârah wa al-Shu'ûbah, Aman: Dâr al-yazûri al'ilmiyah, 2006.

Zamel, V. "Writing: The Process of Discovering Meaning", TESOL Quarterly, 16 (2), 1982.
Para-phrase untuk Meningkatkan

Kemampuan Apresiasi dan Menulis Puisi. EdisiKhusus. No. 2, 2011.

Rubin, J. "What the "Good Language Learner" Can Teach Us", TESOL Quarterly, 9 (1), 1975.

S.M Aqil Burney. Inductive and deductive research approach, www.drburney.net, March 62008.

Sadi, F. F, Othman. J. "An Investigation into Writing Strategies of Iranian EFL Undergraduate Learners", World Applied Sciences Journal, Vol. 18 (8), 2012.

Sadiq Askari. "Al-Ma'âyir al-Manhajiyyah al-Mathlûbah li al-Nasyr al-Maq'âl'ât al-'Ilmiyah", Majallah ad-Dirâsât fî alLughah al-Arabiyyah wa Adabihâ, No. XIX, 2014.

Suparti. "Strategi Pembelajaran Menulis di Sekolah Dasar Kelas IV", Didaktika, Vol. 2, No. 1, 2007.

Swain, M. \& Lapkin, S. "Problems in Output and Cognitive Processes They Generate: a Step Towards Second Language Learning", Applied Linguistics, 16, 1995. 